\title{
ACRL supports sister libraries Strengthening relationships across borders
}

$\mathrm{W}$ ould you like to increase the stature of your library, gain publicity, provide better service, reach out globally, and collect hard to find materials? Then sister libraries is for you!

We're so pleased Camila Alire has chosen to make ACRL's support of sister libraries an important part of her ter $\mathrm{m}$ as ACRL President. At the 2005 ALA Annual Conference, the ACRL Board of Directors
ACRL signed with the National Council of Higher Education Libraries of Mexico (CONPAB-IES) in 2003, the initial focus of the agreement will be on finding U.S. libraries to partner with Mexican libraries.

By participating in the sister libraries program, academic and research librar ies c an strengthen existing relationships between their institutions and others. Con-

\section{Reasons to become a sister library and build a partnership with a library in another country}

- Promote awareness of the library and its international "reach."

- Exchange information between your library and its sister library.

- Improve access to published information in both countries.

- Raise awareness of issues and needs facing libraries in various countries.

- Offer opportunities to learn more about a region or country represented by an immigrant group in your community.
- Share techniques and technologies to help solve problems.

- Broaden both your own and your staff's view of the library profession.

- Increase staff and community knowledge of other cultures.

- Increase diversity of interaction between professionals.

- Share strengths through exchange of resources and expertise.

- Address weaknesses by providing resources, training, and exposure. endorsed a declaration encouraging institutions to explore sister library partnerships and to build relationships with libraries in other cultures that can help us lear n, understand, and better serve our own communities.

The Board char ged the ACRL Inter national Relations Committee (IRC) with raising awareness of the benefi ts of working with sister libraries to the ACRL community. To further the cross-border agreement sider study abroad programs, international degree partnerships, research institutes or centers, and the makeup of the population you serve. The program is fexible to allow

Kara Malenfant is ACRL's scholarly communications/ government relations specialist and immediate pastchair of ACRL's IRC, e-mail: kmalenfant@ala.org, and Heleni Pedersoli, is librarian for Western European and Latin American studies at the University of Maryland and a member of ACRL's IRC, e-mail: pedersol@umd.edu.

๑) 2005 Kara Malenfant and Heleni Pedersoli 
libraries to define their own relationships with their sister libraries. ALA's Inter national Relations Office provides a Web site to facilitate matches, highlight tips, and feature success stories. It plans to include sample agreements, as well.

\section{Sister libraries in action}

In early July, the libraries at Universidad Anáhuac in Mexico City, Mexico, and St. Ambrose University in Davenport, Iowa, agreed to be sister libraries, and they are very excited about their new venture. Both are private, Catholic universities with similar programs. They say the sister libraries program could lead to broader partnerships between their universities' study abroad and faculty exchange programs.

ACRL IRC is working in conjunction with the ALA International Relations Round Table (IRRT) Sister Libraries Committee to promote and foster sister library relationships among academic and research libraries. IRRT Sister Libraries plans to hold a discussion group and poster session for ALA Annual Conference in 2006, and ACRL will showcase successful academic relationships there.

To generate more interest among ACRL members and Mexican academic libraries, ACRL IRC is working to secure funding and provide seed grants to encourage nascent sister library relationships between U.S. and Mexican libraries. Look for more news on that later this year.

\section{Why not become a sister library?}

We urge ACRL members to explore sister library relationships and ACRL sections and units to support this ef fort. Please spread the word among your membership and prominently link the IRR T Sister Libraries Web page to your Web sites.

Libraries can search for potential sister libraries or complete a request for $\mathrm{m}$ and become part of the database at ALA's Sister Libraries W eb site: www.ala.org/ala /ourassociation/othergroups/sisterlibraries /sisterlibraries.htm. $\boldsymbol{z}$

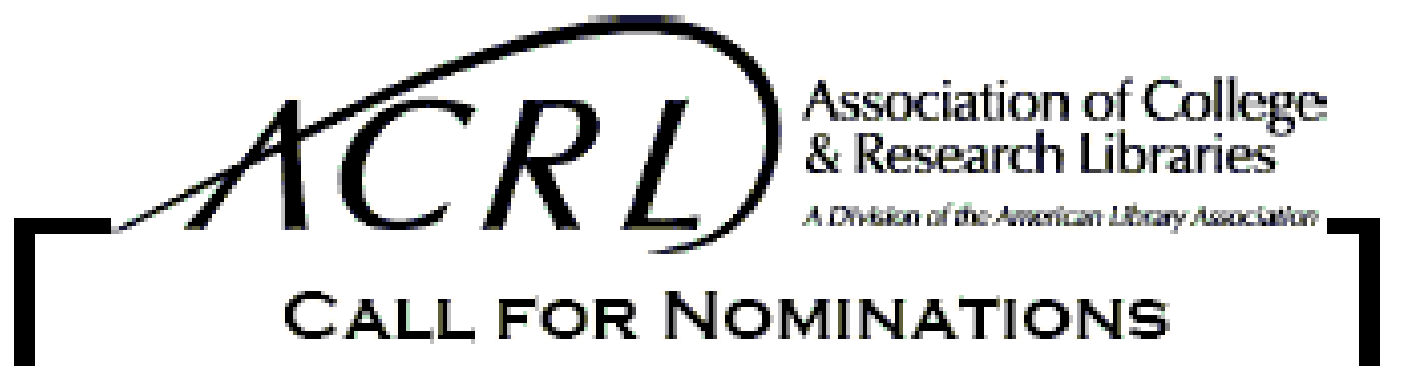
EXCELLENCE IN ACADEMIC LIBRARIES AWARD $\$ 3,000$ and a plaque
Sponsored by Blachwell's Book Services

ACADEMIC OR RESEARCH LIBRARIAN OF THE YEAR

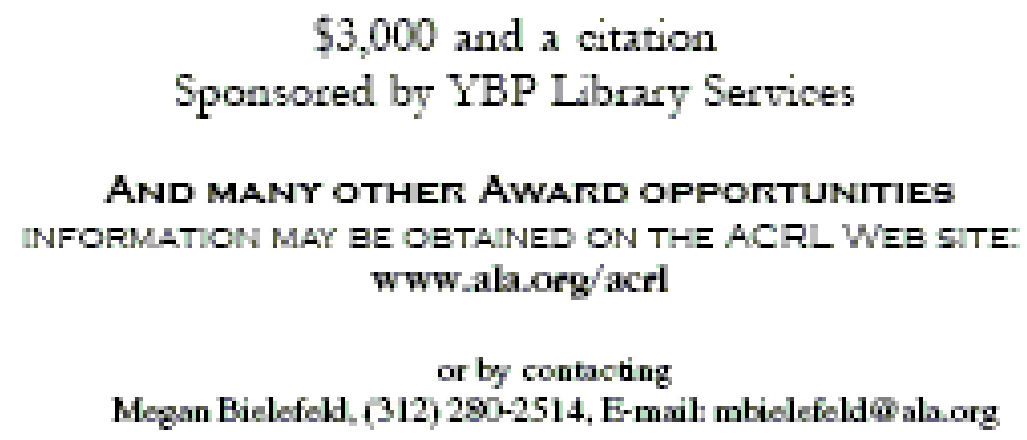

